\title{
ON A NEW INEQUALITY SIMILAR TO HARDY-HILBERT'S INEQUALITY
}

\author{
BICHENG YANG
}

Abstract. In this paper, a new inequality similar to Hardy-Hilbert's inequality with a best constant factor is given. As applications, we consider its equivalent form and their associated integral inequalities.

Mathematics subject classification (2000): $26 \mathrm{D} 15$. inequality.

Key words and phrases: Hardy-Hilbert's inequality, weight coefficient, weight function, Hölder's

\section{REFERENCES}

[1] G. H. Hardy, J. E. Littlewood and G. Polya, Inequalities, Cambridge Univ. Press, Cambridge, 1952.

[2] D. S. MitrinoviC, J. E. PECARIC AND A. M. FINK, Inequalities Involving Functions and There Integrals and Derivatives, Kluwer Academic Publishers, Boston, 1991.

[3] Yang Bicheng And Gao Mingzhe, On a best value of Hardy-Hilbert's inequality, Adv. Math. 262 (1997), 159-164.

[4] Gao Mingzhe And Yang Bicheng, On the extended Hilbert's inequality, Proc. Amer. Math. Soc. 126 3 (1998), 751-759.

[5] YANG Bicheng AND L. DeBnath, On new strengthened Hardy-Hilbert's inequality, Internat. J. Math. Math. Sci. 211 (1998), 403-408.

[6] YANG BICHENG, On an extension of Hardy-Hilbert's inequality, Chin. Annal. Math. 23A (2002), 247-254.

[7] YANG BICHENG, On new generalizations of Hilbert's inequality, J. Math. Anal. Appl. 248 (2000), 29-40.

[8] KUANG JiCHENG AND L. DeBNATH, On new generalizations of Hilbert's inequality and their applications, J. Math. Anal. Appl. 245 (2000), 248-265.

[9] H. P. Mullholland, Some theorems on Dirichlet series with positive coefficients and related integrals, Proc. London Math. Soc. 292 (1929), 281-292.

[10] Kunng Jicheng, Applied Inequalities, Hunan Education Press, Changsha, 1992. 